\title{
Role of orthotopic heart transplantation in the management of patients with recurrent ventricular tachyarrhythmias following myocardial infarction
}

\author{
J P Bourke, A Loaiza, G Parry, C Hilton, S Furniss, J Dark, J Forty
}

\begin{abstract}
Objective-To report the outcome of an intention to treat by heart transplantation strategy in two groups of patients after infarction, one with both left ventricular failure (LVF) and ventricular tachyarrhythmias (VTA) (group A) and the other with progressive LVF following antiarrhythmic surgery for VTA (group B).
\end{abstract}

Patients and methods-Group A comprised 17 consecutive patients for whom transplantation was considered the best primary non-pharmacological treatment; group $B$ comprised five consecutive patients assessed and planned for transplantation after antiarrhythmic surgery.

Results-In group A, eight patients underwent transplantation and all survived the first 30 day period. At median follow up of 55 months (range 11 to 109) seven of this subgroup were still alive. Five patients died of recurrent VTA before transplantation, despite circulatory support. In the face of uncontrollable VTA, four of these underwent "high risk" antiarrhythmic surgery while awaiting transplantation: three died of LVF within 30 days and one was saved by heart transplantation two days after arrhythmia surgery. Mortality for the transplantation strategy in group $A$ patients was $47 \%$ by intention to treat analysis. Quality of life in the eight actually transplanted, however, was good and only one died during median follow up of 56 months. The five patients in group $B$ were accepted for transplantation for progressive LVF at a median of 21 months (range 12 to 28 ) after antiarrhythmic surgery. One died of LVF before transplantation, 22 months after initial surgery; another died of high output LVF three days after transplantation. Thus mortality of the intended strategy was $40 \%$. The three transplanted patients are alive and well at 8-86 months.

Conclusions-Although the short and medium term outcome in category $A$ or $B$ patients who undergo transplantation is good, the overall success of the transplantation strategy in category $A$ patients is limited by lack of donors in the short time frame in which they are required. (Heart 1998;80:473-478)

Keywords: heart transplantation; ventricular arrhythmias; myocardial infarction
Patients who present with episodes of either sustained ventricular tachycardia or fibrillation against a background of established heart failure following myocardial infarction have a very poor prognosis. ${ }^{1-3}$ Drug treatment is used to improve ventricular function and prevent sudden death, but it is largely ineffective in the long term..$^{4-7}$ Map guided antiarrhythmic surgery, combined with aneurysmectomy and myocardial revascularisation, can improve the outlook for some patients in this category, but the perioperative mortality from low output cardiac failure is high, despite control of arrhythmias. ${ }^{8-10}$ Implantable cardioverter defibrillators (ICD) have been a major therapeutic advance and, in some patients, achieve control of arrhythmias with an operative mortality of less than $1 \% .{ }^{11}{ }^{12}$ However, the ability of even ICDs to prevent arrhythmic deaths in these patients is limited ${ }^{13}$ and purely antiarrhythmic measures have little impact on survival in patients who remain in overt heart failure despite optimum medical treatment. Cardiac transplantation could provide the best overall treatment for selected patients in this category, curing both arrhythmias and heart failure. However, the appropriateness and resource implications of accepting such patients on to a heart transplant programme need careful consideration, given the chronic shortage of donors. $^{14} 15$

In this report we describe our experience of the use of heart transplantation in two categories of patients with postinfarction ventricular tachyarrhythmias - first, as primary nonpharmacological treatment in patients referred to the arrhythmia service with a combination of arrhythmias and heart failure; and second, as treatment for patients with progressive heart failure following map guided surgical endocardial resection.

\section{Methods}

Patients referred for assessment of serious ventricular tachyarrhythmias following myocardial infarction were assessed to determine whether the best treatment was pharmacological, cardioverter defibrillator implantation, map guided endocardial resection, or heart transplantation. The treatment recommended was determined by factors including the patient's age and overall medical status, the perceived life threat posed by arrhythmia recurrences, the residual function of non-infarcted left ventricular segments, and the extent of coronary artery disease. All of these methods of treatment were available within the institution. The choice of 
treatment recommended was thus not influenced by the range of treatments available on site. Map guided endocardial resection was first performed at our hospital in 1980, the cardiac transplant programme began in 1985, the first cardioverter defibrillator was implanted in 1990, and radiofrequency catheter ablations for postinfarction ventricular tachycardia began in about 1995 .

CRITERIA FOR ANTIARRHYTHMIC SURGERY

From 1980 to 1985 , map guided endocardial resection was offered to all patients whose arrhythmias were considered to pose a life threat, despite optimum drug treatment. It was also performed in a small number of patients when cardiac surgery was required for another primary indication, even though arrhythmias were responsive to drug treatment. ${ }^{16}{ }^{17}$ With the availability of heart transplantation in 1985 and implantable defibrillation in 1990, elective surgical treatment is now reserved for patients without important comorbidity who also have normal systolic function in at least three of nine left ventricular segments on their biplane left ventricular cine-angiogram. ${ }^{8}$ However, emergency surgery continued to be offered to patients without other therapeutic options throughout the period of the data collection.

CRITERIA FOR CARDIOVERTER DEFIBRILLATOR IMPLANTATION

After 1990, device treatment was offered to patients with infrequent arrhythmias and severely impaired left ventricular function as defined above, and to those with comorbidity likely to result in a significant increase in mortality after antiarrhythmic surgery. However, defibrillator treatment was not used in patients with frequently recurring arrhythmias or in those who remained in heart failure (Killip class III-IV; New York Heart Association (NYHA) class IV) despite medical treatment.

CRITERIA FOR HEART TRANSPLANTATION

In the period 1986 to 1987 , heart transplantation became an option for patients with poor cardiac reserve and symptomatic heart failure, who had survived a life threatening episode of ventricular tachyarrhythmia and whose anticipated mortality from conventional antiarrhythmic surgery was considered unacceptably high (group A). It was also available for patients, who had previously undergone antiarrhythmic surgery but who later became progressively limited by heart failure (group B). To be considered for transplantation, however, patients had to meet the standard criteria applied to all potential recipients.

CRITERIA FOR RADIOFREQUENCY CATHETER ABLATION

Although some catheter ablations had been performed using direct current for many years at our hospital, radiofrequency ablations for supraventricular tachycardias only became routine from 1992 and for ventricular tachycardia from about 1995. Thus catheter ablation was not considered during much of the period of data collection, even in patients with haemodynamically well tolerated forms of ventricular tachycardia.

MANAGEMENT WHILE AWAITING HEART

TRANSPLANTATION

While awaiting transplantation, patients at high arrhythmia risk remained in hospital with continuous telemetered ECG rhythm supervision. To improve left ventricular function antiarrhythmic drugs were withdrawn and all patients were maintained on diuretics and angiotensin converting enzyme inhibitors, with or without intermittent nitrate treatment. ${ }^{10} 18$ Dobutamine infusions were often used but other inotropes were avoided in view of their arrhythmogenic potential. Digoxin was used only in patients with atrial fibrillation. If major episodes of arrhythmia recurred, antiarrhythmic drug treatment was restarted and temporary pacing was sometimes instituted to aid arrhythmia control. Intra-aortic balloon pump support was used in some patients to support left ventricular function and to reduce arrhythmia frequency. ${ }^{19}$ If frequent arrhythmias continued, antiarrhythmic surgery was recommended unless the patient was considered to have a negligible chance of surviving this procedure.

Patients undergoing transplantation for progressive heart failure occurring late after antiarrhythmic surgery were managed as outpatients in the same way as other categories of potential recipients. Recipient waiting time was calculated from the time that transplantation was considered optimum treatment in group A, and from the date of acceptance onto the transplant list in group B, to the date of transplantation, arrhythmia surgery, or death.

HEART TRANSPLANTATION AND SUBSEQUENT FOLLOW UP

Conventional orthotopic heart transplantation was performed with triple therapy immunosuppression. ${ }^{20}$ The follow up programme required monthly cardiac biopsies for three months, three monthly biopsies for one year, and annual biopsies thereafter. Coronary angiography was undertaken two years after transplantation and annually thereafter. Follow up on all patients transplanted is complete, as all were kept under regular review by the transplant team until death.

STATISTICAL ANALYSIS

Comparisons between subgroups were performed using the unpaired $t$ test. Differences were considered significant at the 5\% level and highly significant at the $1 \%$ level. Survival curves were drawn from actuarial survival calculations using Statview version 4.5 (Abacus Concepts Inc, Berkeley, California, USA).

\section{Results}

TRANSPLANTATION FOR ARRHYTHMIAS AND HEART FAILURE AFTER MYOCARDIAL INFARCTION In the period 1987 to 1996 , heart transplantation was considered optimum treatment for 17 patients referred to the electrophysiology service with the combination of severely 
Table 1 (A-C) Heart transplantation as primary treatment for ventricular tachyarrhythmias and heart failure following myocardial infarction

(A) Actually transplanted $(n=8)$

\begin{tabular}{lllllllllllll}
\hline Age/sex & MI-N & $\begin{array}{l}\text { First VT } \\
\text { present }\end{array}$ & $\begin{array}{l}\text { VTA } \\
\text { number }\end{array}$ & $\begin{array}{l}\text { Tx waiting } \\
\text { (days) }\end{array}$ & KC & CADs & $\begin{array}{l}\text { LVEF } \\
(\%)\end{array}$ & WMS & CI & $\begin{array}{l}\text { Tx } \\
\text { (+/-) }\end{array}$ & $\begin{array}{l}\text { F-up } \\
\text { (months) }\end{array}$ & Status \\
\hline $52 / \mathrm{M}$ & 2 & Arrest & 16 & 44 & II & 2 & 28 & 2 & 2.0 & + & 109 & Alive \\
$51 / \mathrm{M}$ & 3 & Arrest & 3 & 92 & II & 2 & 16 & 2 & 2.7 & + & 103 & Alive \\
$51 / \mathrm{M}$ & 4 & Arrest & 5 & 111 & III & 2 & 18 & 2 & 1.2 & + & 92 & Alive \\
$42 / \mathrm{M}$ & 4 & Tolerated & 24 & 35 & III & 2 & 16 & 1 & 2.7 & + & 56 & Died (MI) \\
$59 / \mathrm{M}$ & 1 & Arrest & 10 & 52 & IV & NA & 15 & 0 & 3.1 & + & 54 & Alive \\
$56 / \mathrm{M}$ & 2 & Tolerated & 5 & 30 & I & 1 & 15 & 0 & 2.6 & + & 17 & Alive \\
$59 / M$ & 4 & Tolerated & 1 & 28 & I & 3 & 18 & 1 & 1.6 & + & 11 & Alive \\
$60 / M$ & 2 & Tolerated & 1 & 20 & IV & NA & NA & 1 & 2.9 & + & 33 & Alive \\
\hline
\end{tabular}

(B) Died of arrhythmias awaiting transplantation $(n=5)$

\begin{tabular}{|c|c|c|c|c|c|c|c|c|c|c|c|}
\hline Age/sex & $M I-N$ & $\begin{array}{l}\text { First VT } \\
\text { present }\end{array}$ & VTA number & $\begin{array}{l}\text { Tx waiting } \\
\text { (days to death) }\end{array}$ & $K C$ & $C A D s$ & $\begin{array}{l}\text { LVEF } \\
(\%)\end{array}$ & $W M S$ & $C I$ & $\begin{array}{l}T x \\
(+/-)\end{array}$ & $\begin{array}{l}\text { LV support } \\
\text { deployed }\end{array}$ \\
\hline $50 / \mathrm{M}$ & 2 & Tolerated & Intractable $\times 24 \mathrm{~h}$ & 2 & IV & 2 & 10 & 0 & NA & - & IABP \\
\hline $38 / \mathrm{M}$ & 1 & Tolerated & $\geqslant 4$ & 7 & II & 1 & NA & 2 & NA & - & PC bypass \\
\hline $62 / \mathrm{F}$ & 1 & Arrest & $\geqslant 5$ & 18 & IV & 2 & 15 & 2 & 2.9 & - & IABP/pacing \\
\hline $59 / \mathrm{M}$ & 1 & Tolerated & Intractable & 11 & II & 3 & $<25$ & 0 & NA & - & IABP/pacing \\
\hline $57 / \mathrm{F}$ & 2 & Arrest & Intractable $\times 48 \mathrm{~h}$ & 13 & IV & NA & 26 & NA & NA & - & Dobutamine \\
\hline
\end{tabular}

(C) High risk arrhythmia surgery undertaken $(n=4)$

\begin{tabular}{|c|c|c|c|c|c|c|c|c|c|c|c|}
\hline Age/sex & $M I-N$ & $\begin{array}{l}\text { First VT } \\
\text { present }\end{array}$ & $\begin{array}{l}\text { VTA } \\
\text { number }\end{array}$ & $\begin{array}{l}\text { Tx waiting } \\
\text { (days to death) }\end{array}$ & $K C$ & $C A D s$ & $\begin{array}{l}\text { LVEF } \\
(\%)\end{array}$ & WMS & $C I$ & $\begin{array}{l}T x \\
(+/-)\end{array}$ & $\begin{array}{l}L V \text { support } \\
\text { deployed }\end{array}$ \\
\hline $49 / M$ & 1 & Arrest & Incessant & 12 & I & 1 & 235 & 2 & NA & - & IABP + LVAD \\
\hline $54 / \mathrm{F}$ & 1 & Tolerated & Incessant & 7 & IV & 1 & 5 & 0 & NA & - & IABP \\
\hline $52 / \mathrm{M}$ & 1 & Collapse & 6 & 11 & IV & 1 & 17 & 5 & NA & - & IABP; dopamine \\
\hline $43 / \mathrm{M}$ & 1 & Arrest & 7 & 2 & IV & 1 & $<10$ & 0 & NA & + & $\mathrm{LVAD} \rightarrow \mathrm{T} \mathrm{x}$ \\
\hline
\end{tabular}

Arrest, cardiac arrest; CADs, number of major coronary arteries with stenoses $>75 \%$; CI, cardiac index $\left(1 / \mathrm{min} / \mathrm{m}^{2}\right)$; First VT present, clinical presentation of the first arrhythmic episode; F-up, duration of follow up after cardiac transplantation; IABP, intra-aortic balloon pump device; KC, Killip classificication of heart failure (I-IV); LVAD, left ventricular assist device; LVEF, \% left ventricular ejection fraction; MI, myocardial infarction; MI-N, number of confirmed myocardial infarctions; NA, data not available; PC bypass, percutaneous cardiopulmonary bypass; Tolerated, haemodynamically tolerated + syncope; $\mathrm{Tx}(+/-)$, whether cardiac transplantation performed; WMS, left ventricular segments with normal systolic motion (1=9).

compromised left ventricular function and life threatening ventricular arrhythmias after myocardial infarction (group A). Table 1 summarises the clinical and arrhythmia characteristics of the group, and their outcome is summarised in fig 1.

Eight patients eventually received transplants (table 1A), five died of arrhythmia recurrences while awaiting transplantation (table 1B), and four underwent "salvage" antiarrhythmic surgery in the face of intractable arrhythmias while awaiting a suitable donor (table 1C). All those transplanted survived the first 30 days after the operation. Their median times from last infarction and first arrhythmic episode to transplantation were 13 and 3.5 months, respectively. The mean waiting time for a donor heart was 49

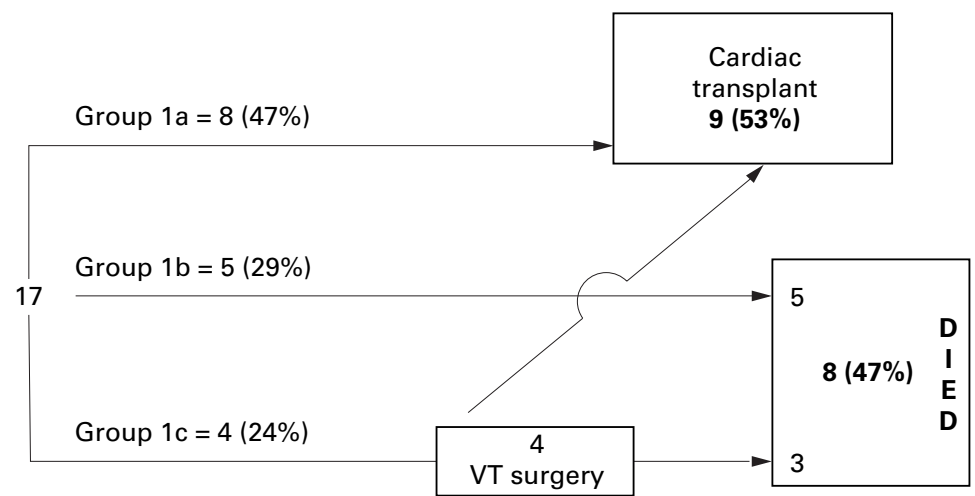

Figure 1 Group A patient management. Group 1a, patients actually transplanted; group $1 b$, patients who died before transplantation; group 1c, patients who underwent "salvage" surgery for ventricular tachycardia. These groups correspond with $A-C$ in table 1. days (range 22 to 111 days). One had an unsuccessful radiofrequency catheter ablation attempt while awaiting transplantation. During median follow up of 55 months (range 11 to 109), only one of these eight patients had died at the time of writing. Death followed a myocardial infarction 4.7 years after transplantation.

Five patients died of recurrent arrhythmias before a suitable donor became available. None of these was considered suitable even for salvage surgery or catheter ablation. This group survived a median of only 10 days (range 2 to 18) from the time of acceptance for transplantation (table 1B) despite intra-aortic balloon pump support in three and percutaneous bypass in one. Median times from last infarction and first arrhythmia episode in these patients were 1.5 months and 14 days respectively.

In the context of uncontrollable recurrent arrhythmias while awaiting transplantation, four patients underwent high risk salvage antiarrhythmic surgery. Their median times from last infarction and first arrhythmic episode to surgery were 11.5 and 10.5 months, respectively. Three died of heart failure in the early postoperative period and the fourth survived only by undergoing heart transplantation 48 hours after the operation (table 1C).

Although none of the nine patients actually transplanted died in the early postoperative period, the mortality for the strategy of treating this type of patient by "urgent" heart transplantation was $47 \%$ (eight of 17) by intention 
Table 2 Transplantation for heart failure after previous antiarrhythmic surgery

\begin{tabular}{|c|c|c|c|c|c|c|c|c|c|c|}
\hline Age/sex & VT-op type & $\begin{array}{l}\text { VT-op to Tx or } \\
\text { death (months) }\end{array}$ & $\begin{array}{l}\text { Days on } \\
\text { active Tx list }\end{array}$ & $K C$ & $\begin{array}{l}\text { CADs pre } \\
\text { VT-op }\end{array}$ & $\begin{array}{l}\text { LVEF } \\
(\%)\end{array}$ & $W M S$ & $C I$ & $\begin{array}{l}T x \\
(+/-)\end{array}$ & $\begin{array}{l}\text { Status } \\
\text { (follow up) }\end{array}$ \\
\hline $54 / \mathrm{M}$ & $\mathrm{ER} ; \mathrm{C} \times 4$ & 22 & 107 & IV & 3 & 32 & 2 & 2.0 & + & Died (3 d) \\
\hline $60 / \mathrm{M}$ & ER; Cryo; C $\times 3$ & 28 & 120 & IV & 3 & 28 & 4 & 2.0 & + & Alive $(8 \mathrm{~m})$ \\
\hline $58 / \mathrm{M}$ & $\mathrm{ER} ; \mathrm{C} \times 5$ & 21 & 547 & II & 3 & 26 & 1 & 1.8 & + & Alive $(15 \mathrm{~m})$ \\
\hline $58 / \mathrm{M}$ & ER; Anx; C×2 & 12 & 50 & IV & 3 & 29 & 3 & 2.0 & + & Alive $(86 \mathrm{~m})$ \\
\hline $54 / \mathrm{M}$ & $\mathrm{ER} ; \mathrm{C} \times 2$ & 16 & 79 & IV & 2 & 29 & 3 & 2.0 & - & Died of LVF \\
\hline
\end{tabular}

Anx, aneurysmectomy; C, coronary artery bypass grafts; CADs, extent of coronary artery disease; CI, cardiac index; ER, map guided endocardial resections; KC, Killip class of heart failure; LVEF, left ventricular ejection fraction; LVF, left ventricular failure; Tx $(+/-)$, cardiac transplantation performed or not; VT-op, antiarrhythmic surgery; WMS, wall motion score.

to treat analysis. Figure 2 relates outcome to recipient waiting time for each subgroup. As might be anticipated, patients who died had waited a shorter time for a suitable donor than those actually transplanted $(\mathrm{p}=0.007)$.

\section{ELECTIVE HEART TRANSPLANTATION AFTER}

ANTIARRHYTHMIC SURGERY

The second category of patients studied were those considered for heart transplantation in the context of progressive heart failure after map guided surgical endocardial resection for postinfarction arrhythmias in the period 1988 to 1996. Five patients were referred and accepted for elective transplantation after antiarrhythmic surgery (group B). Their clinical details are summarised in table 2. Four had been rendered arrhythmia-free by antiarrhythmic surgery for a median period of 21 months (range 12 to 28). The fifth patient had required repeated hospital admission for initially well tolerated ventricular tachycardia with resultant progressive congestive heart failure. Between episodes this patient was in NYHA class II. He was managed at a time when catheter ablation was not available for ventricular tachycardia.

One patient died of progressive heart failure 79 days after listing for heart transplantation. The remaining four were transplanted after waits of between 60 and 547 days. One of these died of unexplained high output heart failure, unresponsive to treatment, three days after transplantation. On an intention to treat basis, therefore, the periprocedural mortality from cardiac transplantation as an adjunct to antiarrhythmic surgery in this small series was $40 \%$ (two of five). This compares with a combined waiting list and 30 day postoperative mortality of $28 \%$ for patients undergoing elective heart transplantation at this unit. The mean waiting time for a suitable donor in such patients follows a bimodal distribution, with a median of 120 days. The three who survived the perioperative period were well at the time of writing, at intervals of between eight months and seven years after transplantation.

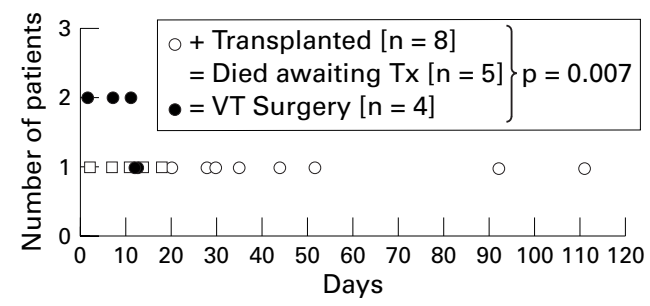

Figure 2 Outcome in relation to recipient waiting time in group A patients.

\section{Discussion}

Theoretically, heart transplantation is the ideal treatment for patients with life threatening ventricular tachyarrhythmias and irreversible heart failure following myocardial infarction. Several reports refer to the possibility of transplantation in this type of patient, while others report outcome in those actually transplanted. ${ }^{21-25}$ Determining the value of the transplantation strategy on an intention to treat basis is more difficult, not least because of the problems in defining when a patient actually becomes a potential transplant recipient for inclusion in any analysis. For the purpose of this analysis, we included all patients who were transferred to the electrophysiology service at our hospital for management and whose optimum treatment was considered to be heart transplantation rather than continued drug treatment, antiarrhythmic surgery, or device treatment. This population may not be the same as one selected by referral to a heart transplant service from the start. Three patients who died before transfer to our hospital were excluded. The aim of this intention to treat analysis was to determine the unit's ability to use heart transplantation in a cohort of patients with overt heart failure, who developed serious ventricular arrhythmias after myocardial infarction.

\section{RESULTS IN PATIENTS PROCEEDING TO}

TRANSPLANT

The benefits of heart transplantation in this group of patients are confirmed by the long term survival and good functional status in all nine patients in group A who actually underwent transplantation. ${ }^{22} 23$ Their median follow up to date is 55 months with a range of 11 months to nine years. One patient died 56 months after transplantation following an anterior myocardial infarction complicated by heart failure and arrhythmias. It is unlikely that any would have survived more than a year without transplantation and four were in NYHA class III-IV heart failure before surgery. $^{3}{ }^{15}$

\section{RESULTS OF TRANSPLANT STRATEGY BY}

INTENTION TO TREAT ANALYSIS

The ability to use heart transplantation as primary treatment for arrhythmias in the context of heart failure is limited by the scarcity of suitable donors. ${ }^{36}$ Eight of the 17 patients in group A died of arrhythmias after waiting times of only two to 18 days. This compares with waiting times of between 20 and 111 days in those successfully transplanted $(p=0.0073)$. 
Attempts to support those who died-using intra-aortic balloon pumps, percutaneous bypass, or left ventricular assist devices-were largely unsuccessful. While status was improved briefly in all but one patient, the need to wean patients from support later because of the development or risk of complications was followed by re-emergence of arrhythmias. ${ }^{27}$ Ischaemic leg complications after a week of balloon pump support contributed to the death of one patient in this series.

There is controversy over when to initiate support and how much support is appropriate in these patients. ${ }^{28-33}$ While supportive measures are undoubtedly helpful in the short term, the need for central lines or temporary pacing wires, balloon pumps, percutaneous bypass, or left ventricular assist devices all increase immobility and the risk of sepsis, which would preclude transplantation. ${ }^{303134-36}$

If mechanical hearts ${ }^{29} 30$ or xenotransplantation $^{37} 38$ become available in the future they could, by being readily deployable, transform the initial outcome in these patients. However, the longer term outcome of these treatments would also need to match that of orthotopic transplantation. ${ }^{39} 40$

\section{HIGH RISK ARRHYTHMIA SURGERY IN PLACE OF} HEART TRANSPLANTATION

High risk antiarrhythmic surgery to "salvage" patients from arrhythmic death when a donor is not available seems inadvisable. Three of the four patients in whom this was undertaken died of low output heart failure despite left ventricular assistance. The fourth, already supported by a left ventricular assist device, would also have died had not a suitable donor become available 48 hours after antiarrhythmic surgery. This type of patient is not the same as those requiring antiarrhythmic surgery because of intractable arrhythmias in the early weeks after infarction, with preserved function in the noninfarcted segments. ${ }^{161-43}$ Their outcome following antiarrhythmic surgery is likely to be determined more by the extent of residual contractile function than by arrhythmia frequency preoperatively.

CATHETER ABLATION AND THE IMPLANTABLE DEFIBRILLATOR AS BRIDGES TO TRANSPLANTATION Only one patient in group A underwent attempted radiofrequency catheter ablation for ventricular tachycardia, mainly because the technique only became available during the latter part of the data collection. However, even now, radiofrequency catheter ablation is primarily intended for patients with haemodynamically well tolerated ventricular tachycardia. ${ }^{44-46}$ Therefore by this criterion alone, nine group A patients would not have been candidates for ablation on the basis of their initial presentation, and several whose initial presentation was with stable tachycardia subsequently experienced cardiac arrest with other arrhythmia morphologies after admission. Furthermore, the cycle length of tachycardia was no indicator of its haemodynamic tolerability in patients with this degree of left ventricular dysfunction. Nevertheless, catheter ablation is likely to become a useful adjunct in stabilising these patients and thereby allowing them to survive to transplantation.

There have been several reports of the value of implantable cardioverter defibrillators in preventing arrhythmic deaths during the waiting period for heart transplantation, ${ }^{45}{ }^{46}$ and three patients have now also been treated in this way in our unit. In such patients, transplantation may be delayed safely until heart failure symptoms can no longer be controlled adequately by medical means. The unpredictability of organ availability, however, still results in occasional patients undergoing transplantation within weeks of device implantation, where the cost of continued hospital stay would not have exceeded the device cost.

In contrast to these patients, however, device therapy in patients already severely limited by heart failure symptoms despite optimal drug treatment, or in those with frequent arrhythmia episodes, is neither appropriate nor cost effective. ${ }^{47}$ The majority of the patients described in group A of this report who did not survive to transplantation were in this category. Indeed in some of these, ventricular arrhythmias reflect the terminal phase of heart failure rather than being a correctable or specifically treatable electrophysiological entity.

\section{HEART TRANSPLANTATION AFTER}

ANTIARRHYTHMIC SURGERY

That three of five patients became long term survivors after heart transplantation for progressive heart failure late after antiarrhythmic surgery confirms a complementary role for these two types of surgery in selected patients. However, the fact that one patient died before transplantation, and another within days of it, emphasises that this treatment is not always successful. ${ }^{13} 1548$

Failure of left ventricular function to improve after antiarrhythmic surgery identifies a subgroup likely to develop progressive heart failure over the next two years. Identifying those suitable for transplantation by this criterion alone might allow them to go on the waiting list at an earlier stage and thus reduce the mortality. However, the majority of patients with postinfarction arrhythmias are not candidates for heart transplantation because they are elderly and have pulmonary or diffuse vascular comorbidity. Forty of the first 100 patients who underwent antiarrhythmic surgery for postinfarction ventricular tachycardia in our unit were more than 60 years old, and 20 were more than 64 years old. The majority of these patients survived the early postoperative period, returned to a high functional status, and had a low annual cardiac mortality until coronary graft disease progressed to cause further myocardial infarction. During long term follow up, 11 died of progressive cardiac failure unrelated to reinfarction. At the time of death, only five of these would have been candidates for transplantation on age criteria alone. Thus the best estimate from our unit is that some $5 \%$ of patients after arrhythmia surgery for postinfarction ventricular tachyarrhythmias might subsequently become candidates for transplantation. 
This analysis confirms a small but important role for heart transplantation as primary treatment for younger patients with recurrent, drug refractory ventricular tachyarrhythmias, in the context of overt heart failure after myocardial infarction. It is most appropriate, and more likely to be successful, in patients who have infrequent arrhythmia episodes, as they are likely to survive the wait for a suitable donor. Cardiac transplantation also has an important role as adjunctive treatment for patients with progressive heart failure after arrhythmia surgery.

The University Department of Cardiology is supported by the British Heart Foundation.

1 Cleland JGF, Dargie HJ, Ford I. Mortality in heart failure: clinical variables of prognostic value. Br Heart $\mathcal{f}$ 1987;58:572-82

2 Juul-Moller S, Lilja B, Johansson BW. Ventricular arrhythmias and left ventricular function: one-year follow-up after myocardial infarction. Eur Heart $\mathcal{f}$ 1988;9:1181-7.

3 Hori M, Koretsune Y, Takemura K, et al. Prognosis of patients with severe congestive heart failure referred to the cardiac transplant program. Osaka University Cardiac Transplant Program. Fpn Circ 7 1994;58:395-402

4 Chakko S, Gheorghiade M. Ventricular arrhythmias in severe heart failure: incidence, significance and effectiveness of therapy. Am Heart $\mathcal{F}$ 1985;109:497-504.

5 Rae AP, Greenspan AM, Spielman SR, et al. Antiarrhythmic drug efficacy for ventricular tachyarrhythmias associated drug efficacy for ventricular tachyarrhythmias associated
with coronary artery disease as assessed by electrophysiwith coronary artery disease as assessed by
ologic studies. Am f Cardiol 1985;55:1494-9.

6 Bourke JP, Cowan JC, Tansuphaswadikul S, et al. Antiarrhythmic drug effects on left ventricular performance. Eur Heart F 1987;8(suppl A):105-11.

7 Velebit V, Podrid P, Lown B, et al. Aggravation and provocation of ventricular arrhythmias by antiarrhythmic drugs. Circulation 1982;65:886-94.

8 van Hemel NM, Kingma JH, Defauw JJ, et al. Left ventricular segmental wall motion score as a criterion for selecting patients for direct surgery in the treatment of post-
infarction ventricular tachycardia. Eur Heart $\mathcal{F} 1989 ; 10$ : 304-15.

9 Garan H, Nguyen K, McGovern B, et al. Perioperative and long-term results after electrophysiologically directed ventricular surgery for recurrent ventricular tachycardia. $7 \mathrm{Am}$ Coll Cardiol 1986;8:201-9.

10 Cox JL. Patient selection criteria and results of surgery for refractory ischaemic ventricular tachycardia. Circulation refractory ischaemic ventricu

11 Gabry MD, Brodman R, Johnstone D, et al. Automatic implantable cardioverter-defibrillator: patient survival, battery longevity and

12 Kelly PA, Cannom DS, Garan $\mathrm{H}$, et al. The automatic cardioverter-defibrillator: efficacy, complications and survival in patients with malignant ventricular arrhythmias. $\mathcal{F}$ Am Coll Cardiol 1988;11:1278-86.

13 Huagui L, Axtell K, Bieh IM, et al. Sudden death in patients with implantable cardioverter-defibrillators. Am Heart $f$ 1996;132:986-8.

14 Copeland JG. Cardiac transplantation after 60 years of age. Ann Thorac Surg 1988;45:115-16.

15 Mullins PA, Scott JP, Dunning JJ, et al. Cardiac transplant waiting lists, donor shortage and retransplantation and implications for using donor hearts. Am F Cardiol 1991;68: 408-9.

16 Bourke JP, Hilton CJ, McComb JM, et al. Surgery for control of recurrent life-threatening ventricular tachyarrhythmias within two months of myocardial infarction. $₹ \mathrm{Am} \mathrm{Coll}$ mias within two months
Cardiol 1990;16:42-8

17 Bourke JP, Campbell RWF, Renzulli A, et al. Surgery for ventricular tachyarrhythmia based on fragmentation mapping in sinus rhythm alone. Eur F Cardiothorac Surg 1989;3. $401-7$

18 Mackinnon G, Landymore R, Marble A. Should oral amiodarone be used for sustained ventricular tachycardia in patients requiring open-heart surgery. Can f Surg 1983;26: 355-7.

19 Sanfelippo PM, Baker NH, Ewy HG, et al. Experience with intra-aortic balloon counterpulsation. Ann Thorac Surg 1986;41:36-41

20 Cabrol C, Gandjbakhch I, Pavie A, et al. Current problems in cardiac transplantation. Clin Transplants 1987:27-32.

21 Gallagher JJ, Selle JG, Svenson RH, et al. Surgical treatment of arrhythmias. Am $\mathcal{F}$ Cardiol 1988;61:27-44A.
22 Steinbeck G, Haberl R, Kemkes BM. Heart transplantation in drug resistant recurrent ventricular tachycardia and fibrillation. $Z$ Kardiol 1987;76:479-83.

23 Zamora BH, Garrote AJ, Salvador AJ, et al. The surgical treatment of sustained ventricular tachycardias. The shortand midterm results in the era of the implantable defibrillator and the heart transplant [in Spanish]. Revista Espanola de Cardiologia 1994;47:227-38.

24 Frank G, Lowes D, Beaumont D, et al. Surgical alternatives in the treatment of life-threatening ventricular arrhythmias. Eur f Cardiothorac Surg 1988;2:207-16.

25 Vigano M, Graffigna A, Salerno G. Surgery for refractory ischaemic arrhythmia. Giornale Italiano di Cardiologia 1992;22:373-80.

26 Stevenson LW, Hamilton MA, Tillisch IH, et al. Decreasing survival benefit from cardiac transplantation for outpatients as the waiting list strengthens. I Am Coll Cardiol 1991;18:919-25.

27 Parascandola SA, Pae WE, Davis PK, et al. Determinants of survival in patients with ventricular assist devices. ASAIO Trans 1988;34:222-8.

28 Pennington DG, McBride LR, Peigh PS, et al. Eight years' experience with bridging to cardiac transplantation. F Thorac Cardiovasc Surg 1994;107:472-80.

29 Joyce LD, Johnson KE, Toninato CJ, et al. Results of the first 100 patients who received Symbion total artificial hearts as 100 patients who received Symbion total artificial hearts as 192-201.

30 Curtis JJ, Walls JT, Schmaltz R, et al. Experience with the Sanns centrifugal pump in post-cardiotomy ventricular failure. $\mathcal{F}$ Thorac Cardiovasc Surg 1992;104:554-60.

31 Costard-Jackle A, Hill I, Schroeder JS, et al. The influence of preoperative patient characteristics on early and late survival following cardiac transplantation. Circulation 1991; 84(suppl 5):I-329-37.

32 Helmuth RA, Strate RW, Waller BF, et al. Death occurring within one week of cardiac transplantation: findings in eight patients. Indiana Med 1991;84:480-3.

33 Farrar DJ, Holl D, Gray LA, et al. Successful biventricular circulatory support as a bridge to cardiac transplantation during prolonged ventricular fibrillation and asystole. Circulation 1989;80(suppl III):III-147-151.

34 Hill JD. Bridging to cardiac transplantation. Ann Thorac Surg 1989;47:167-71

35 Griffith BP, Kormas RL, Hardesty RL, et al. The artificial heart: infection related morbidity and its on transplantation. Ann Thorac Surg 1988;45:409-14.

36 Copeland JG, Smith RG, Icenogle TB, et al. Early experience with the total artificial heart as a bridge to cardiac transplantation. Surg Clin North Am 1988;68:621-34.

37 Aufiero TX, Reddy RC, Magovern JA, et al. Alternatives to human heart replacement. Curr Opin Cardiol 1995;10:21822.

38 Millan MT, Ferran C, Winkler H, et al. Xenotransplantation: problems and approaches. Transplant Proc 1994;26:3593-6.

39 Frimpong-Boateng K, Haverich A, Schafers HJ, et al. Results of orthotopic heart transplantation for ischaemic cardiomyopathy. Eur f Cardiothorac Surg 1987:1:98-103

40 Heublein B, Haverich A, Borst HG. Long-term follow-up after orthotopic heart transplantation. Thorac Cardiovasc Surg 1990;38:285-90.

41 Di Marco JP, Lerman BB, Kron IL, et al. Sustained ventricular tachyarrhythmias within 2 months of acute myocardial infarction: results of medical and surgical therapy in patients resuscitated from the initial episode. $\mathcal{F}$ Am Coll Cardiol 1985;6:759-68.

42 Miller JM, Marchlinski FE, Harken AH, et al. Subendocardial resection for sustained ventricular tachycardia in the early period after acute myocardial infarction. Am f Cardiol $1985 ; 55: 980-4$

43 Garan H, Ruskin JN, DiMarco JP, et al. Refractory ventricular tachycardia complicating recovery from acute myocardial infarction: treatment with map-guided infarctectomy. Am Heart f 1984;107:571-7.

44 Harada T, Stevenson WG, Kocovic DZ, et al. Catheter ablation of ventricular tachycardia after myocardial infarction: relation of endocardial sinus rhythm late potentials to the reentry circuit. F Am Coll Cardiol 1997;30:1015-23.

45 Stevenson WG, Khan H, Sager P, et al. Identification of reentry circuit sites during catheter mapping and radiofrequency ablation of ventricular tachycardia late after myocardial infarction. Circulation 1993;88:I-1647-70.

46 Blanchard SM, Walcott GP, Wharton JM, et al. Why is catheter ablation less successful than surgery for treating ventricular tachycardia that results from coronary artery disease? PACE 1994;17:2315-35.

47 Sweeney MO, Ruskin JN, Garan H, et al. Influence of the implantable cardioverter-defibrillator on sudden death and total mortality in patients evaluated for cardiac transplantation. Circulation 1995;92:3273-81.

48 Wahlers T, Cremer J, Fieguth HG, et al. Donor heart-related variables and early mortality after heart transplantation. $\mathcal{F}$ Heart Lung Transplant 1991;10:22-7. 